Quim. Nova, Vol. 34, No. 8, 1394-1397, 2011

\title{
PROPERTIES OF SILICA FROM RICE HUSK AND RICE HUSK ASH AND THEIR UTILIZATION FOR ZEOLITE Y SYNTHESIS
}

\author{
Jan-Jezreel F. Saceda and Rizalinda L. de Leon \\ Department of Chemical Engineering, College of Engineering, University of the Philippines, Quezon City, 1101, Philippines \\ Kamolwan Rintramee, Sanchai Prayoonpokarach and Jatuporn Wittayakun* \\ School of Chemistry, Institute of Science, Suranaree University of Technology, Nakhon Ratchasima 30000, Thailand
}

Recebido em 21/12/10; aceito em 22/3/11; publicado na web em 10/6/11

\begin{abstract}
This study compared properties of silica $\left(\mathrm{SiO}_{2}\right)$ from rice husk $(\mathrm{RH})$ and rice husk ash (RHA) extracted by acid- and heat-treatment. The $\mathrm{SiO}_{2}$ from $\mathrm{RH}$ was in amorphous phase with nearly $100 \%$ purity while that from RHA was in crystalline phase with $97.56 \%$ purity. Both extracted $\mathrm{SiO}_{2}$ were used in the synthesis of zeolite $\mathrm{NaY}$ but that from $\mathrm{RH}$ was better due to the efficiency in product recovery and simplicity of extraction. After the $\mathrm{NaY}$ was exchanged to $\mathrm{NH}_{4} \mathrm{Y}$ and calcined to convert to $\mathrm{HY}$, the product did not carry over the textural properties of the parent $\mathrm{NaY}_{\text {and }} \mathrm{NH}_{4} \mathrm{Y}$.
\end{abstract}

Keywords: silica; rice husk; rice husk ash.

\section{INTRODUCTION}

Zeolite $\mathrm{Y}$ is a type of zeolite in faujasite family and widely known for its use as an adsorbent and as catalyst. ${ }^{1}$ It is also commonly used as a catalyst support because of its thermal stability and acidity. ${ }^{2,3}$ Zeolite $\mathrm{Y}$ can be synthesized by using various sources of silica $\left(\mathrm{SiO}_{2}\right)$. A range of commercial silica sources are available varying from compound, fumed and colloidal forms. ${ }^{3}$ We previously reported the synthesis of zeolite $\mathrm{Y}$ in sodium form (NaY) by using silica from rice husk (RH). ${ }^{4}$ Because of the abundance of rice husk ash (RHA) generated from combustion, it would be worthwhile to compare properties of silica from RH and RHA and the utilization for the NaY synthesis.

$\mathrm{RH}$, generally considered as agricultural waste, is mainly used for energy generation, and also used as raw materials to develop technological products such as high purity silica ash, silicon carbide and zeolites. ${ }^{5}$ A major inorganic component of $\mathrm{RH}$ is silica (about 20-30 wt. \%). ${ }^{6}$ Upon leaching with mineral acid and calcination, silica with high purity in amorphous form could be extracted from RH.,7 In the past few years our group used rice husk silica (RHS) in the synthesis of different kinds of zeolites including NaY, BEA, MOR, and mesoporous MCM-41., ${ }^{4,8}$

RHA, derived from burning of RH is also an agricultural excess. RHA is generally used as soil ameliorants to help break up clay soils and improve soil structure but is also used as silica source as an insulator in the steel industry and as a pozzolan in the cement industry. Being less carbonaceous, RHA could be easily coursed through heattreatment to extract amorphous silica. ${ }^{6,7}$ In another couple of studies, RHA containing crystalline tridymite and $\alpha$-cristobalite was used as an alternative silica source for the syntheses of BEA and ZSM-5 zeolites. ${ }^{9}$ A work characterized the ash produced from combustion of rice husk in fluidized bed reactor showing speed and continuity of the process. ${ }^{10}$

The objectives of this paper were to compare the properties of silica from local RH and RHA and the utilization as silica sources for the synthesis of zeolite NaY. The silica and zeolites were characterized by

*e-mail: jatuporn@sut.ac.th x-ray diffraction (XRD), scanning electron microscopy (SEM), energy dispersive $\mathrm{X}$-ray spectroscopy (EDS), and $\mathrm{N}_{2}$ adsorption-desorption analysis. Moreover, the stability of the zeolite upon transformation to ammonium form $\left(\mathrm{NH}_{4} \mathrm{Y}\right)$ by ion exchange and to proton form (HY) after a subsequent calcination was also reported.

\section{EXPERIMENTAL}

\section{Chemicals and materials}

RH and RHA used as raw materials in this work were acquired from a local rice mill and an agricultural store near Suranaree University of Technology, Thailand. The chemicals used for the silica and zeolite $\mathrm{NaY}$ synthesis were hydrochloric acid (37\% $\mathrm{HCl}$, Merck), sodium aluminate $\left(\mathrm{NaAlO}_{2}, 50-56 \% \mathrm{Al}_{2} \mathrm{O}_{3}\right.$, Riedel-de Haen), and sodium hydroxide ( $97 \% \mathrm{NaOH}$ anhydrous pellets, Carlo-Erba). The standard zeolite was $\mathrm{NaY}$ with a $\mathrm{Si} / \mathrm{Al}$ molar ratio 5.7 from JRC, Tosoh Corporation, Japan.

\section{Preparation of silica}

The extraction of silica from $\mathrm{RH}$ was done with a procedure used in our group. ${ }^{4}$ The $\mathrm{RH}$ was washed, dried, refluxed with $3 \mathrm{~mol} \mathrm{~L}^{-1}$ $\mathrm{HCl}$ at $358 \mathrm{~K}$ for $3 \mathrm{~h}$. The resulting $\mathrm{RH}$ was then washed until the filtrate was neutral, dried overnight and calcined at $823 \mathrm{~K}$ for $6 \mathrm{~h}$ to finally produce the rice husk silica (RHS). The same procedure was done on the RHA to extract rice husk ash silica (RHAS) except for the pretreatment washing. RHS and RHAS were dissolved in $\mathrm{NaOH}$ solution and filtered to produce sodim silicate $\left(\mathrm{Na}_{2} \mathrm{SiO}_{3}\right)$ solution with $28 \% \mathrm{w} / \mathrm{w}$ silica and $11 \% \mathrm{w} / \mathrm{w} \mathrm{NaOH}$.

\section{Synthesis of zeolite $\mathrm{NaY}$}

The zeolite $\mathrm{NaY}$ was synthesized by using the $\mathrm{Na}_{2} \mathrm{SiO}_{3}$ solution from RHS and RHAS with a two-step method. ${ }^{4}$ Briefly, a seed gel $\left(\mathrm{Al}_{2} \mathrm{O}_{3}: 10 \mathrm{SiO}_{2}\right)$ was first prepared by adding $\mathrm{Na}_{2} \mathrm{SiO}_{3}$ solution into $\mathrm{NaAlO}_{2}$ solution under stirring until homogenous and left undisturbed 
for $24 \mathrm{~h}$. A feedstock gel $\left(\mathrm{Al}_{2} \mathrm{O}_{3}: 10 \mathrm{SiO}_{2}\right)$ was also prepared the same way but just before the aging of the seed gel would finish. The seed gel was added into the feedstock gel under high-shear stirring until homogeneous gel was obtained. The overall gel was covered and left to age at room temperature for $24 \mathrm{~h}$ before crystallization at $373 \mathrm{~K}$ for another $24 \mathrm{~h}$. Finally, zeolite NaY powder was filtered, washed and dried at $373 \mathrm{~K}$.

\section{Transformation of $\mathrm{NaY}$ to $\mathrm{NH}_{4} \mathrm{Y}$ and $\mathrm{HY}$}

Zeolite $\mathrm{Y}$ in ammonium form, $\mathrm{NH}_{4} \mathrm{Y}$ was prepared by treating the parent $\mathrm{NaY}$ in $1 \mathrm{~mol} \mathrm{~L}^{-1} \mathrm{NH}_{4} \mathrm{NO}_{3}$ solution for $8 \mathrm{~h}$ at $353 \mathrm{~K}$ and kept for $16 \mathrm{~h}$ at room temperature. ${ }^{11}$ The solution was centrifuged, decanted and the exchange was repeated 3 times. The solids obtained after three ion-exchanges was filtered, washed, and then dried to produce zeolite $\mathrm{NH}_{4} \mathrm{Y}$ before it was calcined at $773 \mathrm{~K}$ for $3 \mathrm{~h}$ to finally produce zeolite in proton form (HY).

\section{Characterization of silica sources and zeolites}

The chemical compositions of the prepared RHS and RHAS as well as the synthesized zeolites, calculated as major oxides, were analyzed by EDS (Oxford Instrument ED 2000). The silica and zeolites were carbon-coated before the analysis.

The crystallinity and phase of the silica and the zeolites were determined by XRD (Bruker AXS diffractometer D5005) with nickelfiltered $\mathrm{Cu} \mathrm{K} \alpha$ radiation (wavelength $=1.5406 \AA$ ).

The textural properties of the zeolites were studied by nitrogen adsorption-desorption analysis using a gas adsorption system (Micromeritics ASAP 2010). The zeolite samples were initially degassed at $573 \mathrm{~K}$ under vacuum before the measurements. The analyses were carried out at liquid nitrogen temperature and the specific surface areas were determined from the adsorption data by BET method in the relative pressure range of $0.01-0.30$. The micropore sizes were determined by the t-plot method and pore volumes were calculated from the desorption branches of the isotherms using BJH method.

\section{RESULTS AND DISCUSSION}

\section{Properties and solubility of RHS and RHAS}

After calcination of acid-treated RH, white RHS was produced (Figure 1Sa, supplementary material) with an average yield of $18.07 \%$ by weight based on the onset weight of rice husk. The XRD spectrum of RHS (Figure 2S, supplementary material) showed a broad peak at the $2 \theta$ value of 22 degrees, a characteristic of silica in amorphous form which is suitable for the preparation of sodium silicate solution necessary for zeolite Y synthesis. Amorphous silica is easily dissolved in basic solution even at room temperature in contrast to crystalline silica. ${ }^{12}$ The elemental composition analysis done with EDS showed that the $\mathrm{SiO}_{2}$ was the only detected component in the extracted RHS. In our previous research, the extracted silica from rice husk consisted of approximately $98 \% \mathrm{SiO}_{2}$, as analyzed by x-ray fluorescence spectroscopy (XRF). ${ }^{4}$ The chemical composition analysis from XRF also revealed trace amounts of $\mathrm{K}_{2} \mathrm{O}, \mathrm{Al}_{2} \mathrm{O}_{3}, \mathrm{CaO}$ and $\mathrm{Al}_{2} \mathrm{O}_{3}$ but these were not detected by the EDS used in this study. After $6 \mathrm{~h}$ of silica dissolution in stirred $\mathrm{NaOH}$ solution and subsequent filtration, a clear yellowish viscous sodium silicate solution was produced. Average weight percent recovery of sodium silicate solution after dissolution and filtration was $89.64 \%$.

After the calcination of acid-treated RHA, the RHAS was produced at an average yield of $59.11 \%$ by weight. The as-received RHA samples were black with some gray particles and the resulting RHAS still had black and gray textures after calcination (Figure 1Sb, supplementary material) implying encapsulated carbon residues. Sharp XRD peaks of RHAS at $2 \theta$ values of $20.9,21.9,26.6,31.4$ and $36.0^{\circ}$ indicates silica in crystalline form (Figure 1). These reflections would give corresponding d-values of 4.06, 3.35, 2.85, and 2.49 when used in Bragg's equation. The International Centre for Diffraction Data database reports tridymite $(4.06,3.33$, and 10.9) and cristobalite (4.04, 2.49, and 2.84) reflections. ${ }^{13}$ These XRD peaks, therefore, suggest that the RHAS has mixed phases of both forms of crystalline silica. Ashes from long and high temperature pyrolysis of rice husk are known to contain silica in crystalline form and the silica can be dissolved in basic solution at lower rates and higher temperatures in comparison with the amorphous one..$^{6,12}$

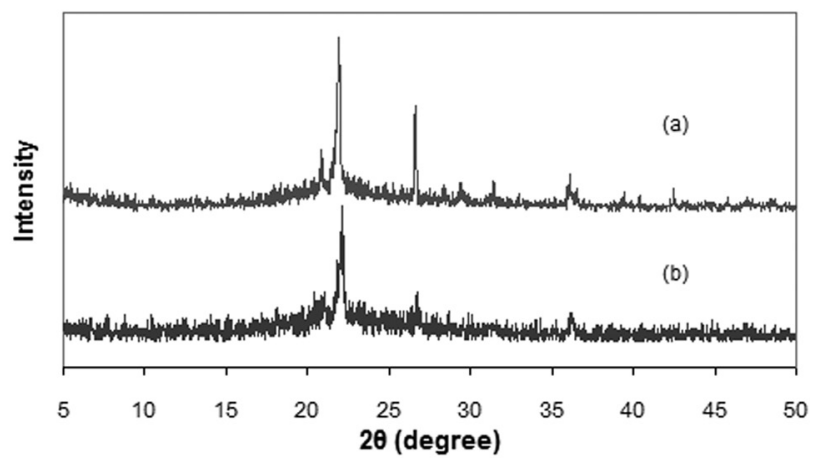

Figure 1. XRD pattern of (a) rice husk ash silica and (b) as-received rice husk ash

At calcination temperatures above $1173 \mathrm{~K}$, the $\mathrm{SiO}_{2}$ in RHA would consist phases of cristobalite and some tridymite because of the melting of the surfaces of ash silica particles and bonding of particles together. ${ }^{14}$ This behavior was demonstrated in the calcination applied here even though the as-received rice husk ash was found to be already in crystalline form according to its XRD spectrum (Figure 1). The as-received RHA only have defined Bragg's peaks at $2 \theta$ value of $21.9^{\circ}$ and some distinct peaks at $20.9,26.6$ and $36.0^{\circ}$. On the other hand, peaks at $20.9,26.6,31.4$ and $36.0^{\circ}$ were more defined in the XRD spectrum of RHAS compared to that of RHS.

After adding RHAS in stirred $\mathrm{NaOH}$ solution, undissolved residue was filtered out indicating poor solubility. The 24-h stirring and dissolution of RHA gave an average percent recovery of sodium silicate solution of only $58.73 \%$ by weight while 48 -h dissolution gave $76.94 \%$ recovery. Despite the relatively low recovery, solution of dissolved silica was nevertheless produced and utilized in the following zeolite synthesis. The level of $\mathrm{SiO}_{2}$ in RHAS, determined by EDS was $97.56 \%$. Since samples for EDS characterization were coated with carbon before analysis, carbon content of the extracted silica, particularly in RHA, cannot be accounted. Aside from $\mathrm{SiO}_{2}$, the RHAS was also found to contain $2.14 \% \mathrm{~K}_{2} \mathrm{O}$ and $0.31 \% \mathrm{Al}_{2} \mathrm{O}_{3}$. In a study of Della et al. using XRF, RHA after calcination at $973 \mathrm{~K}$ for $6 \mathrm{~h}$ has a $\mathrm{SiO}_{2}$ composition of $94.95 \%$. Other detections in their study were $0.94 \% \mathrm{~K}_{2} \mathrm{O}, 0.90 \% \mathrm{MgO}, 0.74 \% \mathrm{P}_{2} \mathrm{O}_{5}, 0.54 \% \mathrm{CaO}$ and some other traces of oxides.

\section{Synthesis of NaY using RHS and RHAS}

Zeolite $\mathrm{NaY}$ were synthesized using the $\mathrm{Na}_{2} \mathrm{SiO}_{3}$ solutions made from RHS and RHAS. The XRD patterns confirmed the characteristic peaks of both zeolite $\mathrm{NaY}$ as compared to that of $\mathrm{NaY}$ standard (Figure 2), and indicated that the zeolites had long-range structure and 
were in pure phase. Both zeolites also had the characteristic peaks of Linde type Y Faujasite published by the International Zeolite Association having strong characteristic reflections at $\mathrm{d}=14.28,8.75$ and $7.46 \AA .{ }^{15}$ This further suggests that the RHAS was soluble in $\mathrm{NaOH}$ solution to some degree even though it was crystalline.

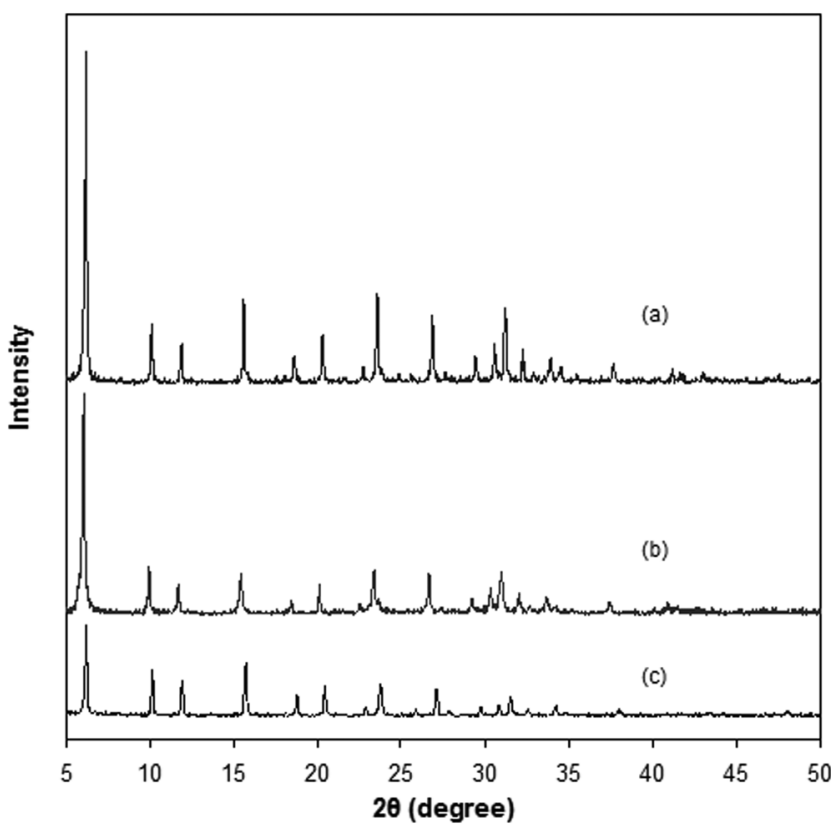

Figure 2. XRD data of zeolite NaY from (a) rice husk and (b) rice husk ash compared with that of (c) standard zeolite $\mathrm{NaY}$ (JRC)

When the zeolite NaY synthesized with RHS was analyzed with EDS, it was found to be composed of $63.04 \% \mathrm{SiO}_{2}, 24.64 \% \mathrm{Al}_{2} \mathrm{O}_{3}$ and $12.28 \% \mathrm{Na}_{2} \mathrm{O}$. This would give silicon to aluminum ratio ( $\mathrm{Si} / \mathrm{Al}$ ) of 2.26. On the other hand, zeolite NaY from RHAS had a composition of $58.52 \% \mathrm{SiO}_{2}, 28.14 \% \mathrm{Al}_{2} \mathrm{O}_{3}$ and $13.37 \% \mathrm{Na}_{2} \mathrm{O}$. This corresponds to $\mathrm{Si} / \mathrm{Al}$ equal to 1.84 which, together with that of zeolite from $\mathrm{RH}$, were near the values of 2.43 suggested in the procedure of Ginter et al.. Zeolite NaY from RHS was used in the study of zeolite transformation because of its higher crystallinity, aside from the higher silica recovery and simplicity in extraction. ${ }^{15}$

\section{Transformation of zeolite $\mathrm{NaY}$ to $\mathrm{NH}_{4} \mathrm{Y}$ and $\mathrm{HY}$}

XRD spectra of $\mathrm{NH}_{4} \mathrm{Y}$ after calcination at different conditions are shown in Figure 3. The zeolite lost much of its long-range structure when it was calcined to produce HY at $773 \mathrm{~K}$. No improvement in retaining the structure when the calcination temperature was reduced to $573 \mathrm{~K}$. However, the peaks were more recognizable when the heating rate was decreased to $2 \mathrm{~K} / \mathrm{min}$.

On two separate studies, van Bokhoven et al. and $\mathrm{Xu}$ et al. investigated the structural collapse of zeolite $\mathrm{Y}$ after subsequent $\mathrm{NH}_{4}{ }^{+}$ion-exchange and calcination. ${ }^{16,17}$ Both studies attributed the loss of long range structure to the formation of local defects sites in the structure and partial dealumination of the zeolite. Xu et al. further explained that the structure collapse of $\mathrm{NH}_{4} \mathrm{Y}$ was from the subsequent exposure to moisture in air which changed the coordination number of aluminum atoms in the zeolite from tetrahedral to octahedral even at room temperature. ${ }^{17}$ They supposed that when post-calcination $\mathrm{HY}$ is exposed to air, a significant fraction of the Al-O bonds are hydrolyzed and broken, leading to a partially amorphous structure and a considerable loss of long-range order and micropore volume.

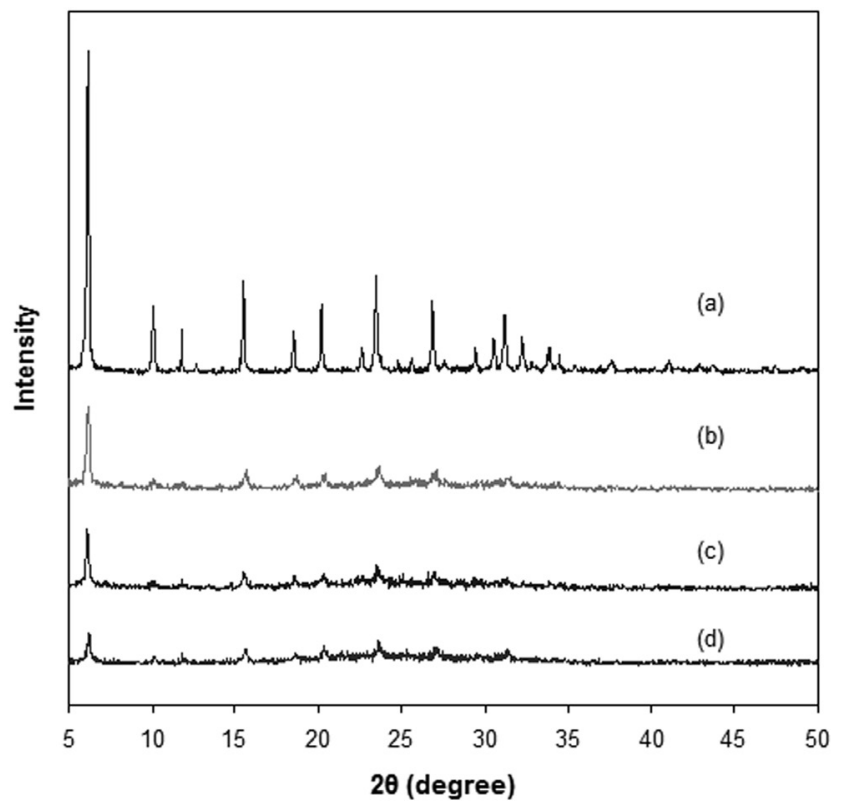

Figure 3. $\mathrm{XRD}$ data of (a) zeolite in ammonium form $\mathrm{NH}_{4} \mathrm{Y}$ synthesized from rice husk silica, and zeolite $\mathrm{NH}_{4} \mathrm{Y}$ calcined at (b) $573 \mathrm{~K}$, heating rate $2 \mathrm{~K} /$ $\mathrm{min}$, (c) $573 \mathrm{~K}$, heating rate $5 \mathrm{~K} / \mathrm{min}$, and (d) $773 \mathrm{~K}$, heating rate $5 \mathrm{~K} / \mathrm{min}$

Table 1. Surface areas and pore volumes of zeolite $\mathrm{NaY}$ and $\mathrm{HY}$ synthesized from rice husk silica

\begin{tabular}{lcc}
\hline Properties & NaY & HY \\
\hline BET surface area $\left(\mathrm{m}^{2} / \mathrm{g}\right)$ & 882 & 363 \\
Micropore area $\left(\mathrm{m}^{2} / \mathrm{g}\right)$ & 809 & 222 \\
Micropore volume $\left(\mathrm{cm}^{3} / \mathrm{g}\right)$ & 0.38 & 0.11 \\
Average pore size $(\AA)$ & 22.4 & 29.0 \\
External surface area $\left(\mathrm{m}^{2} / \mathrm{g}\right)$ & 74 & 141 \\
\hline
\end{tabular}

Physical properties of the synthesized zeolite NaY and HY are summarized in Table 1. The BET surface areas and micropore volumes were estimated from the $\mathrm{N}_{2}$ adsorption-desorption isotherms (Figure $3 \mathrm{~S}$, supplementary material). The adsorption-desorption isotherms of $\mathrm{NaY}$ and HY zeolites exhibited type-I isotherms, characteristic of microporous materials where nitrogen uptake increased quickly at low relative pressure $\left(\mathrm{P} / \mathrm{P}_{0}\right)$ by adsorption in micropores and external surface. After the monolayer adsorption at low $\mathrm{P} / \mathrm{P}_{0}$, the nitrogen uptake was almost constant and a small hysteresis loop at high relative pressure was formed in the adsorption-desorption curves. Hysteresis in adsorption-desorption curves suggested some narrow mesopores in the zeolites. ${ }^{18}$

The BET surface area of NaY zeolite was $882 \mathrm{~m}^{2} / \mathrm{g}$ and micropore volume was $0.38 \mathrm{~cm}^{3} / \mathrm{g}$. Both are characteristic values for a Y-type zeolite framework. However, the HY did not carry over the textural properties of the parent zeolite $\mathrm{NaY}$ and $\mathrm{NH}_{4} \mathrm{Y}$. Slowing down the heating rate on the calcination of $\mathrm{NH}_{4} \mathrm{Y}$ from 5 to $2 \mathrm{~K} / \mathrm{min}$, although it retained some structure as shown in the XRD spectrum, still diminished much of the surface area $\left(363 \mathrm{~m}^{2} / \mathrm{g}\right)$ and micropore volume $\left(0.11 \mathrm{~cm}^{3} / \mathrm{g}\right)$. It is also notable that the average pore size $(29.0 \AA)$ and external surface area $\left(141 \mathrm{~m}^{2} / \mathrm{g}\right)$ of $\mathrm{HY}$ were larger than that of $\mathrm{NaY}$.

The zeolite $\mathrm{HY}$ was found to be composed of $70.75 \% \mathrm{SiO}_{2}$, $26.17 \% \mathrm{Al}_{2} \mathrm{O}_{3}$ and $3.08 \% \mathrm{Na}_{2} \mathrm{O}$ which gave $\mathrm{Si} / \mathrm{Al}$ of 2.39 . The $\mathrm{Si} /$ $\mathrm{Al}$ of $\mathrm{HY}$ is close to that of $\mathrm{NaY}(\mathrm{Si} / \mathrm{Al}=2.26)$ such that the ratio cannot be conclusively identified here as a reason for the difference in thermal stability. Cruciani reviewed factors affecting the thermal stability of zeolites upon heating and observed that the zeolites with 
$\mathrm{Si} / \mathrm{Al}$ ratio of 3.80 or higher are very stable; those with the $\mathrm{Si} / \mathrm{Al}$ ratio of 1.28 or less are quite unstable; and the stability of those with the intermediate $\mathrm{Si} / \mathrm{Al}$ ratio are not predictable from the ratio. ${ }^{19}$

\section{CONCLUSION}

Silica extraction from rice husk $(\mathrm{RH})$ and rice husk ash (RHA) was compared in terms of preparation procedure and yields. Although both are good alternative sources of silica, $\mathrm{RH}$ is the better source than RHA for zeolite NaY synthesis taking into account the efficiency in product recovery and simplicity of extraction. Silica from RH was amorphous whereas that from RHA contained crystalline tridymite and cristobalite. Silica extracted from RH was found to contain exclusively $\mathrm{SiO}_{2}$ while silica from RHA has $97.56 \% \mathrm{SiO}_{2}$ with traces of $\mathrm{K}_{2} \mathrm{O}(2.14 \%)$ and $\mathrm{Al}_{2} \mathrm{O}_{3}(0.31 \%)$. Zeolite $\mathrm{NaY}$ showed relatively large BET surface area of $882 \mathrm{~m}^{2} / \mathrm{g}$ and micropore volume of 0.38 $\mathrm{cm}^{3} / \mathrm{g}$, both are characteristic values for a Y-type zeolite framework. However, HY did not carry over the textural properties of the parent zeolite $\mathrm{NaY}$ and $\mathrm{NH}_{4} \mathrm{Y}$ because of the structure collapse resulting from the change of aluminum coordination in the structure after the calcination.

\section{SUPPLEMENTARY MATERIAL}

Available at http://quimicanova.sbq.org.br, in format PDF, with free access.

\section{ACKNOWLEDGMENT}

This research was supported by Suranaree University of Technology (SUT).

\section{REFERENCES}

1. Cundy, C. S.; Stud. Surf. Sci. Catal. 2005, 57, 65.

2. Trigueiro, F. E.; Monteiro, D. F. J.; Zotin, F. M. Z.; Sousa-Aguiar, E. F.; J. Alloys Compd. 2002, 344, 337.
3. Jansen, J. C.; Stud. Surf. Sci. Catal. 2001, 137, 175.

4. Wittayakun, J.; Khemthong, P.; Prayoonpokarach, S.; Korean J. Chem. Eng. 2008, 25, 861.

5. Foletto, E. L.; Hoffmann, R.; Hoffmann, R. S.; Portugal, U. L.; Jahn, S. L.; Quim. Nova 2005, 28, 1055

6. Della, V. P.; Kühn, I.; Hotza, D.; Mater. Lett. 2002, 57, 818.

7. Della, V.; Hotza, D.; Junkes, J. A.; Oliveira, A. P.; Quim. Nova 2006, 29, 1175.

8. Khabuanchalad, S.; Khemthong, P.; Prayoonpokarach, S.; Wittayakun, J.; Suranaree J. Sci. Technol. 2008, 15, 225; Loiha, S.; Prayoonpokarach, S.; Songsiriritthigun, P.; Wittayakun, J.; Mater. Chem. Phys. 2009, 115, 637; Kulawong, S.; Prayoonpokarach, S.; Neramittagapong, A.; Wittayakun, J.; J. Ind. Eng. Chem. 2011, 17, 182; Chumee, J.; Grisdanurak, N.; Neramittagapong, S.; Wittayakun, J.; Braz. J. Chem. Eng. 2009, 26, 367.

9. Prasetyoko, D.; Ramli, Z.; Endud, S.; Hamdan, H.; Sulikowski, B.; Waste Manage. 2006, 26, 1173; Kordatos, K.; Gavela, S.; Ntziouni, A.; Pistiolas, K. N.; Kyritsi, A.; Kasselouri-Rigopoulou, V.; Microporous Mesoporous Mater. 2008, 115, 189.

10. Martinez, J. D.; Vasquez, T. G.; Junkes, J. A.; Hotza, D.; Quim. Nova 2009, 32, 1110.

11. Chandrasekhar, S.; Pramada, P. N.; Appl. Clay Sci. 2004, 27, 187.

12. Owen, L. B.; Precipitation of Amorphous Silica from High Temperature Hypersaline Geothermal Brines 1975, UCRL-51866.

13. International Centre for Diffraction Data; Powder Diffraction Files 2007.

14. Nakata, Y.; Suzuki, M.; Okutani, T.; Kikuchi, M.; Akiyama, T.; J. Ceram. Soc. Jpn. 1989, 97, 842 .

15. Ginter, D. In Verified Syntheses of Zeolitic Materials; Robson, H., ed.; $2^{\text {nd }}$ ed., Amsterdam, Netherlands, 2001.

16. van Bokhoven, J. A.; van der Eerden, A. M. J.; Koningsberger, D. C.; Stud. Surf. Sci. Catal. 2002, 142.

17. Xu, B.; Rotunno, F.; Bordiga, S.; Prins, R.; van Bokhoven, J. A.; J. Catal. 2006, 241, 66.

18. van Donk, S.; Janssen, A. H.; Bitter, J. H.; de Jong, K. P.; Catal. Rev. 2003, 45, 297.

19. Cruciani, G.; J. Phys. Chem. Solids 2006, 67, 1973. 
PROPERTIES OF SILICA FROM RICE HUSK AND RICE HUSK ASH AND THEIR UTILIZATION FOR ZEOLITE Y SYNTHESIS

Jan-Jezreel F. Saceda and Rizalinda L. de Leon

Department of Chemical Engineering, College of Engineering, University of the Philippines, Quezon City, 1101, Philippines Kamolwan Rintramee, Sanchai Prayoonpokarach and Jatuporn Wittayakun*

School of Chemistry, Institute of Science, Suranaree University of Technology, Nakhon Ratchasima 30000, Thailand

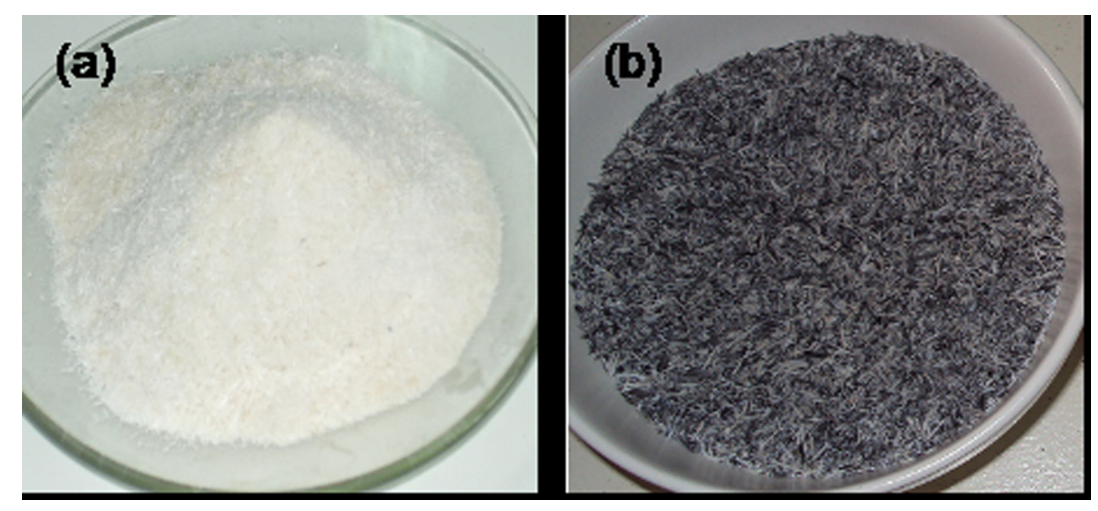

Figure 1S. Macroscopies of (a) RHS and (b) RHAS after acid treatment at reflux for $3 \mathrm{~h}$ and calcination at $823 \mathrm{~K}$ for $6 \mathrm{~h}$

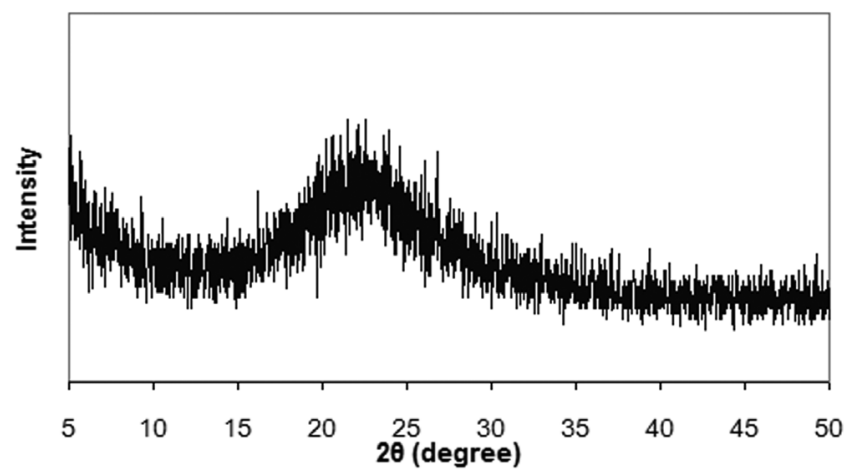

Figure 2S. XRD data of rice husk silica

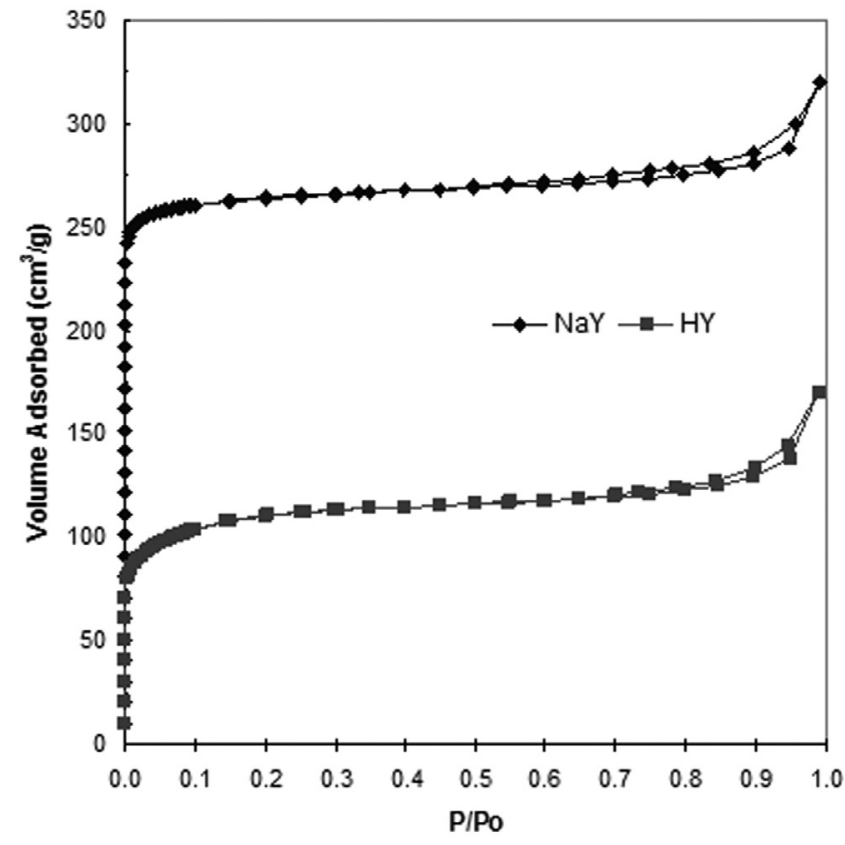

Figure 3S. $\mathrm{N}_{2}$ adsorption-desorption isotherms of zeolite NaY and HY synthesized from rice husk silica 